\title{
Distinguishing me from thee
}

\author{
JOHN H. MUELLER, MICHAEL J. ROSS, and MARTIN HEESACKER \\ University of Missouri, Columbia, Missouri
}

\begin{abstract}
Subjects made self-descriptiveness and other-descriptiveness ratings for the same set of $\mathbf{1 2 0}$ trait adjectives representing three levels of likability. Uniquely descriptive items took longer for self-descriptiveness decisions than did items that were descriptive of both self and other. Although unique features may be spontaneously generated as descriptive of one's self before less distinctive features on unpaced tests, it appears that unique features are accessed more slowly. This result is more consistent with a view that sees trait distinctiveness as being computed rather than prestored.
\end{abstract}

The present study examined the uniqueness of descriptors of one's self or other people. For various reasons, some adjectives may not distinguish one person from another very well. At one extreme, for example, some characteristics may be so desirable or benign that we readily attribute them to many people (e.g., friendly, honorable, witty), or perhaps the attributes are so generally descriptive that they apply to a large number of people (e.g., American, masculine, right-handed). At the other extreme, some characteristics may be so dastardly that we hesitate to attribute them to anyone (e.g., evil, ruthless, wanton), or perhaps, in actuarial terms, we just rarely encounter such people (e.g., acrobatic, dainty, messianic).

Previous work supports the importance of a general distinction between shared and distinctive features of the self concept. For example, McGuire and PadawerSinger (1976) had subjects generate self-descriptions. They found that the features mentioned tended to be those that set a subject apart from other people, not those aspects that were most common. Of course, this does not mean shared features are not a part of our selfconcept, but unique features seemed especially relevant in the course of unpaced spontaneous descriptions. This is not surprising, since the desirability of being different (at least up to a point) has been addressed by many writers (cf. Snyder \& Fromkin, 1980).

This being the case, it seems desirable to examine the way these two types of features, unique and shared, are stored in memory, and how they are accessed. The order of emitting unique and shared features observed by McGuire and Padawer-Singer (1976) might be seen as consistent with the view that unique traits are accessed more readily than shared features. However, unpaced de-

Helpful comments were provided on an earlier draft by Donald Kausler, Richard Petty, and Burt Thompson. Much of the writing of this draft was accomplished while the first author was on sabbatical leave at the University of Queensland, and discussions of this research with many faculty members there were most helpful. Requests for reprints should be sent to J. Mueller, Psychology Department, 210 McAlester Hall, University of Missouri, Columbia, Missouri 65211. scriptions maximize the "editing" of responses, allowing the unique features to dominate output whether they are actually accessed first or not. In other words, free descriptions do not address retrieval speed per se.

One possibility is that information about trait descriptiveness develops from past experience and is "prestored" to expedite access to distinctive features. Such a "strength" model might be conceived as a hierarchy in which traits are arranged by distinctiveness. This view would predict that positive decisions about self-descriptiveness would be more rapid for unique traits than for shared traits, because the more distinctive traits would be stored at the top of the hierarchy.

As sensible as this may seem, we will argue that an alternative conceptualization is more appropriate. In our view, trait distinctiveness is assessed or "computed" at the time of a self-descriptiveness decision, rather than being prestored. This implies that such decisions involve a comparison, perhaps with some abstraction such as "people in general" unless the context provides a more specific target for reference. This idea is also quite plausible, since the distinctiveness of a feature may vary from time to time and place to place (cf. McGuire \& PadawerSinger, 1976). For example, being an American in Paris is much more salient than being an American in Peoria. In terms of trait accessibility, however, this conceptualization predicts that judgments about unique features will be slower than those for shared features. As depicted in Figure 1, a self-reference decision begins with the retrieval of both feature sets and a comparison of them, starting with the intersection of the two sets (i.e., the shared traits). Finding the trait in the intersect (i.e., describes me and thee) yields a fast decision for shared features, whereas failing to find it there leads to a search of the nonoverlapping features, resulting then in either a slow "yes" for a unique characteristic or an even slower "no" response.

The present experiment examined the speed of access to unique and shared features, the critical question being whether unique features were accessed faster or slower than shared or common features. A secondary consideration was whether unique traits are remembered better 


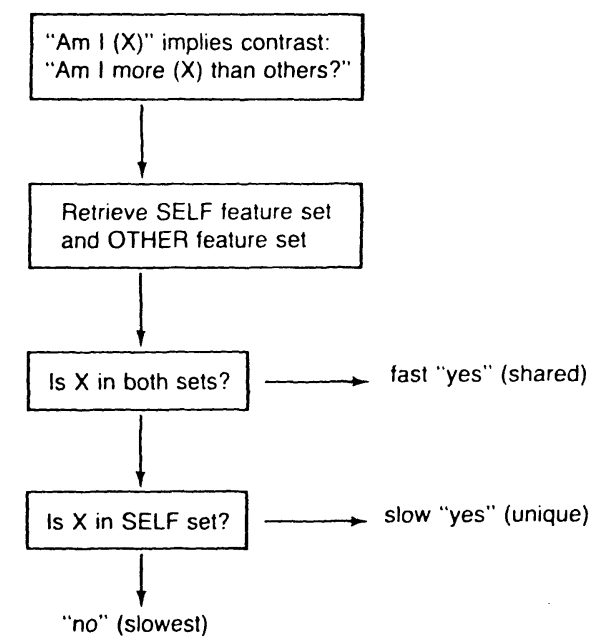

Figure 1. A computational model for the determination of trait distinctiveness.

than shared traits. To operationalize trait "uniqueness," subjects were required to judge the descriptiveness of trait adjectives with themselves as the target and then again with their best friend as the target (or vice versa). Because we probably share more traits with our close friends than with people in general, features that distinguish us from our best friends are likely to be very distinctive. It also seems that the social desirability of the trait could be a factor in determining the willingness to accept it as being personally relevant. Therefore, we included a manipulation of trait likability in this study.

\section{METHOD}

\section{Subjects}

Forty subjects, 21 men and 19 women, participated in return for extra credit in their introductory psychology course. Sex effects were minimal, so this factor will not be considered further.

\section{Materials}

The items rated were 120 trait adjectives selected from the Anderson (1968) norms. Forty words had likability ratings above 4.50 (e.g., capable), and 40 had likability ratings below 1.64 (e.g., rude). The remaining 40 items were selected from the middle of the likability range, with values above 2.02 and below 3.51 (e.g., methodical). For convenience, the latter words will be referred to as "neutral." The rated meaningfulness of the three subsets was comparable (means $=3.69,3.53$, and 3.66 ).

\section{Procedure}

In the rating phase of the study, each subject rated all 120 words for self- (or other-) descriptiveness. Each subject then rated all 120 words a second time for other (or self) descriptiveness. The judgments of other-descriptiveness used "your best friend" as the target. The order of the two targets was varied as first and second tasks across subjects, but because this sequence factor produced no significant effects, it will not be considered further. Each subject saw the 120 adjectives in a different random order, and in a different order for each of the two targets, on a video display controlled by a PDP 11/34 computer. Subjects responded to each word by pressing one of the number keys $(1-8)$ at the top of the keyboard, where 1 was nondescriptive of the target and 8 was descriptive. The subjects were instructed to respond quickly, on the basis of a rapid first impres- sion. To reduce the likelihood of impression management, the experimenter was not present during this phase.

An unannounced recall test followed the rating phase after an interval of about $10 \mathrm{~min}$. The subjects had $10 \mathrm{~min}$ to write down as many of the 120 words as possible, in any order.

The retention interval was filled by the administration of two questionnaires. The first questionnaire was the Self-Consciousness Questionnaire (Buss, 1980). This questionnaire provides an estimate of private self-consciousness, or an individual's proneness to examine moods, motives, etc. Recent studies have shown that subjects who score high on this dimension may perform better than others on self-comparison tasks (e.g., Mueller, 1982; Turner, 1980). It was expected that high scorers might be especially aware of their unique traits, and thus perform more in accord with a prestored view than with a computational view, whereas the reverse would apply for low scorers. The other questionnaire was the State Anxiety Inventory (Spielberger, Gorsuch, \& Lushene, 1970), which yielded no results of interest and will not be discussed further.

\section{RESULTS}

Trait distinctiveness was defined by the combined results of both the self- and the other-descriptiveness judgments, item by item. This analysis involved tabulating the number of words of each of the four subtypes: selfdescriptive and also other-descriptive (Both), selfdescriptive but not other descriptive (Self-Only), not self-descriptive but other-descriptive (Other-Only), and not descriptive of either self or other (Neither). For purposes of analysis, items rated 14 were considered to be nondescriptive, and those rated $5-8$ were considered to be descriptive. The resulting design was a $2 \times 2 \times 3$ factorial, with self (descriptive, nondescriptive), other (descriptive, nondescriptive), and likability (likable, neutral, unlikable) as the three within-subject factors.

\section{Endorsement of Items}

The number of items for each type showed a significant self $x$ other interaction $[F(1,39)=382.06]$. As Table 1 shows, there were a large number of words accepted as being descriptive of both self and the best friend (mean $=46.3$ ), a large number rejected as being descriptive of neither self nor other (mean $=42.6$ ), and considerably fewer adjectives that were descriptive of only one or the other (mean $=18.0$ for Self-Only, and mean $=13.0$ for Other-Only). There were also significant interactions of self $x$ likability $[F(1,78)=417.45]$ and other $x$ likability $[F(1,78)=379.93]$, and a significant interaction of self $\mathrm{x}$ other $\mathrm{x}$ likability $[\mathrm{F}(1,78)=$ 34.82]. The triple interaction indicates (see Table 1) that likability had clear but opposing effects for the mutually descriptive (Both) and mutually nondescriptive (Neither) items, but no clear effects for Self-Only and Other-Only adjectives.

Operationalizing trait distinctiveness in this way, the subjects generated roughly a third of the items as being mutually descriptive of themselves and their best friend, another third as being mutually nondescriptive, and the remaining third as being divided between being uniquely descriptive of either themselves alone or their best friend alone. Perhaps not surprisingly, mutually descriptive items tended to be high in likability, whereas mutually 
Table 1

Number Rated by Mutuality of Self- and Other-Descriptiveness, Latency of Self-Reference Decision, and Probability of Recall

\begin{tabular}{|c|c|c|c|c|c|c|c|c|c|c|c|c|}
\hline \multirow{2}{*}{$\begin{array}{c}\text { Self-Other } \\
\text { Descriptiveness } \\
\text { Types }\end{array}$} & \multicolumn{4}{|c|}{ Number of Each Type } & \multicolumn{4}{|c|}{ Latency (in Milliseconds) } & \multicolumn{4}{|c|}{ Probability of Recall } \\
\hline & $\mathbf{L}$ & $\mathbf{N}$ & $\mathrm{U}$ & All & $\mathrm{L}$ & $\mathrm{N}$ & $\mathrm{U}$ & All & $\mathrm{L}$ & $\mathrm{N}$ & $\mathbf{U}$ & All \\
\hline Both & 31.2 & 12.0 & 3.1 & 46.3 & 3009 & 3575 & 3307 & 3297 & .26 & .18 & .32 & .25 \\
\hline Self Only & 5.5 & 8.3 & 5.5 & 18.0 & 3316 & 3644 & 3486 & 3482 & .28 & .16 & .19 & .21 \\
\hline Other Only & 3.2 & 5.3 & 4.5 & 13.0 & 3376 & 3922 & 3530 & 3622 & .31 & .20 & .23 & .25 \\
\hline Neither & 1.4 & 14.5 & 26.8 & 42.6 & 3510 & 3577 & 3132 & 3395 & .34 & .16 & .23 & .23 \\
\hline
\end{tabular}

Note-Both refers to a word rated as descriptive of self and other; self only refers to a word rated as descriptive of self but not descriptive of other; other only refers to a word that was not self-descriptive, but was other-descriptive; and neither refers to a word descriptive of neither self nor other. $L=$ likable; $N=$ neutral; $U=$ unlikable.

rejected items were generally low in likability. However, items that were more discriminating showed little effect due to likability, although perhaps they were somewhat more "neutral" than likable or unlikable. For example, $46 \%$ of the Self-Only items and $41 \%$ of the Other-Only items were neutral, whereas only $26 \%$ of the Both items were neutral. In contrast, $67 \%$ of the Both items were likable, compared with $31 \%$ and $25 \%$ for Self-Only and Other-Only, respectively.

\section{Latency of Self-Reference}

The speed of making a self-descriptiveness decision was analyzed within the self (yes, no) $x$ other (yes, no) $x$ likability design. Neither the self nor the other main effect was significant $\left(F_{s}<1.50\right)$, but the self $\mathrm{x}$ other interaction was significant $[F(1,39)=7.11]$. Decision speed was faster for nondiscriminating items (means = 3,297 and $3,395 \mathrm{msec}$, for Both and Neither, respectively) than for discriminating items (means $=3,486$ and $3,622 \mathrm{msec}$, for Self-Only and Other-Only, respectively). In the individual comparison of greatest interest, the Self-Only items $(3,482 \mathrm{msec})$ and Both items $(3,297$ msec) were significantly different ( $p<.05$, Tukey test). Thus, it appears that rapid self-reference decisions are made only for items that are generally descriptive, and that decisions about unique features require more time. This result is clearly inconsistent with a "prestore" view of trait distinctiveness.

The likability main effect was significant $[F(2,78)=$ 12.40], because likable items produced the fastest decisions (mean $=3,283 \mathrm{msec}$ ), followed by unlikable items (mean $=3,358 \mathrm{msec}$ ) and neutral items (mean = $3,680 \mathrm{msec}$ ). The other $\mathrm{x}$ likability interaction was significant $[\mathrm{F}(2,78)=3.70]$, with positive (i.e., descriptive) decisions for likable and unlikable items requiring less time than negative (i.e., nondescriptive) deci- sions, whereas positive decisions about neutral items actually took more time than negative decisions.

\section{Recall}

The probability of recall revealed a significant main effect of likability $[F(2,39)=9.81]$, with both likable words $($ mean $=.29)$ and unlikable words $($ mean $=.25)$ being recalled better than neutral words (mean $=.17$ ). The triple interaction of self $\mathrm{x}$ other $\mathrm{x}$ likability was marginally significant $[F(2,78)=5.57, p<.07]$. As can be seen in Table 1, the likability effect was pronounced for the shared traits (Both and Neither), with neutral items being depressed relative to both likable and unlikable items. A different pattern emerged for the SelfOnly and Other-Only subsets: Likable items were recalled better than the neutral or unlikable items, with the latter two levels of likability not differing.

Although items can be distinguished in terms of the specificity of self-descriptiveness, uniqueness appears to make little difference in recall, pooled over likability. However, there were some differences by likability level: Unlikable items showed almost a two-fold difference in probability of recall between Self-Only and Both (means $=.19$ vs. $.32, \mathrm{p}<.05$ ). Furthermore, the Self-Only likability gradient for recall does not resemble the flat likability gradient for that subcategory in terms of the number of items rated as Self-Only, and the likability gradients for recall and number do not match for the Both subcategory. In short, likability had little effect on willingness to endorse an attribute as being uniquely descriptive, but it still had an effect on the subsequent recall of unique traits.

\section{Level of Self-Consciousness}

Table 2 presents correlational data for level of selfconsciousness, by self-other type and likability level.

Table 2

Correlations with Private Self-Consciousness Scores

\begin{tabular}{|c|c|c|c|c|c|c|}
\hline \multirow{2}{*}{$\begin{array}{c}\text { Self-Other } \\
\text { Descriptiveness Types }\end{array}$} & \multicolumn{3}{|c|}{ Probability of Recall } & \multicolumn{3}{|c|}{ Self-Reference Latency } \\
\hline & L & $\mathrm{N}$ & $\mathrm{U}$ & $\mathbf{L}$ & $\mathrm{N}$ & $\mathrm{U}$ \\
\hline Both & -.01 & .03 & -.29 & .10 & .17 & .01 \\
\hline Self Only & $.31 *$ & .06 & .16 & .11 & .16 & .23 \\
\hline Other Only & -.19 & .13 & .15 & $.33 *$ & .11 & -.03 \\
\hline Neither & .05 & .13 & .11 & .28 & .08 & .09 \\
\hline
\end{tabular}


As can be seen, there was only one significant correlation for probability of recall, and it showed that high private self-consciousness was associated with better recall of the likable items that were uniquely self-descriptive. There was a second correlation of marginal significance, in that high self-consciousness was negatively correlated with the recall of mutually descriptive unlikable traits.

The level of private self-consciousness was positively correlated with the speed of self-reference decisions for Other-Only items, and marginally so for the mutually nondescriptive items.

\section{DISCUSSION}

In this experiment, every trait was rated for self-descriptiveness and for other-descriptiveness, which made it possible to distinguish traits that were unique aspects of one's self-concept from traits that, although self-descriptive, were more broadly descriptive as well. Considering the accessibility of shared and unshared traits, the critical result of interest was that judgments were more rapid for shared features than for unique features. For every level of likability in Table 1, Self-Only items took more time for a self-reference decision than mutually descrip tive (Both) items. This is not consistent with models that assume trait distinctiveness is prestored in the self-schema. It appears that some other conceptualization is necessary, one that incorporates the idea that distinctiveness is to some extent computed as self-referencing occurs.

There is even reason to suspect that the unique-shared difference obtained here would be larger when the Both items were mutually descriptive in the extreme sense of the examples discussed earlier (e.g., male, American, etc.). In fact, there is even a prediction in the model in Figure 1 relevant to this point, concerning when the difference between unique-feature and shared-feature latencies would be greatest (smallest). Specifically, when there is considerable overlap between the Self and Other feature sets (compare the self and best-friend endorsements, Table 1), then the difference between unique and shared reaction times will diminish, because there will be less to search after the intersect has been examined. Conversely, if the overlap is small (e.g., self and Ayatollah Khomeini), then the uniqueshared differential in reaction times should increase because searching the intersect will require very little time, leaving many features to be examined.

The question arises as to the generality and reliability of these results, as well as alternative interpretations. As to the reliability of the difference in reaction time for Self-Only and Both items, it appears that the slower speed of access for unique traits is reproducible. Mueller and Ross (1984), using the same adjectives, procedures, and target other (best friend) as were used here, observed that elderly subjects took longer for SelfOnly items than for Both items. It also seems this result holds for several variations in procedures. Ross, Mueller, and de la Torre (1984), using a different word list, "yes" and "no" decisions, and Ronald Reagan and "most students" as targets in two studies, observed a similar result when they compared nondepressed and depressed subjects, and Mueller and Thompson (1984) obtained a similar result when they used a third set of adjectives and a generalized other ("most students") for reference. The only result we are aware of that directly conflicts with these was that reported by Breckler and Greenwald (1981). However, in their procedure, the subjects made judgments of self- and other-descriptiveness successively for each word. The judgments here were made in two separate and discrete phases of the experiment, which should have provided more independent decisions, reduced self-presentation biases, and minimized semantic priming effects.

This leaves the questions of generalization and interpretation. As noted earlier, others (e.g., McGuire and Padawer-Singer, 1976) have argued that situational factors may produce variation in which features of the self emerge as being most important. Furthermore, a recent paper by Srull and Gaelick (1984) provided further evidence favoring a computational determination of trait similarity. Thus, it appears that this viewpoint receives support from several perspectives, involving quite different methodologies. The model in Figure 1 provides a way of understanding this comparative process, although other ways surely can be formulated.

Of course, trait "distinctiveness" can be defined in other ways. For example, subjects can be asked to rate the importance to their self-concept of a given trait, or traits might be ranked in terms of self-descriptiveness. Kuiper (1981) found an inverted-U function for judgment time, with traits rated most and least descriptive of self taking less time for self-reference decisions than did traits of intermediate descriptiveness. Although this seems to conflict with the present finding that decisions were slower for distinctive traits than for shared traits, it is important to realize that trait distinctiveness was defined quite differently in the two cases. That is, Self-Only items may be considered more distinctive than Both items, but, even among the Both items, there may be traits that a subject values as being especially important or Self-Only traits that the subject might prefer to ignore or otherwise undervalue. Therefore, the shared-nonshared classification assesses distinctiveness somewhat differently from the way rating descriptiveness does, and consequently the apparent conflict in results is likely to be related to the different operations used to define "uniqueness" and "degree of descriptiveness."

\section{REFERENCES}

ANDE RSON, N. H. (1968). Likableness ratings of 555 personalitytrait words. Journal of Personality and Social Psychology, 9, 272-279.

Breckler, S. J., \& Greenwald, A. G. (1981). Favorable selfreferent judgments are made faster than non-favorable ones. Paper presented at the meeting of the Midwestern Psychological Association, Detroit, MI.

Buss, A. H. (1980). Self consciousness and social anxiety. San Francisco: Freeman.

KUIPER, N. A. (1981). Convergent evidence for the self as a prototype: The "inverted-U RT effect" for self and other judgments. Personality and Social Psychology Bulletin, 7, 438-443.

McGuire, W. J., \& Padawer-Singer, A. (1976). Trait salience in the spontaneous self-concept. Journal of Personality and Social Psychology, 33, 743-754.

Mueller, J. H. (1982). Self awareness and access to material rated as self-descriptive or nondescriptive. Bulletin of the Psychonomic Society, 19, 323-326.

Mueller, J. H., \& Ross, M. J. (1984). Uniqueness of the selfconcept across the life span. Bulletin of the Psychonomic Society, 22, 83-86.

Mueller, J. H., \& Thompson, W. B. (1984). Test anxiety and distinctiveness of personal information. In H. M. van der Ploeg, R. Schwarzer, \& C. D. Spielberger (Eds.), Advances in test anxiety research (Vol. 3). Lissa: Swets-Zeitlinger/Erlbaum.

Ross, M. J., Mueller, J. H., \& DE lA Torre, M. (1983). Depression and uniqueness of features in the self schema. Manuscript submitted for publication.

SNyder, C. R., \& Fromkin, H. L. (1980). Uniqueness: The human pursuit of difference. New York: Plenum Press.

Spielberger, C. D., Gorsuch, R. L., \& Lushene, R. E. (1970). Manual for the State-Trait Anxiety Inventory. Palo Alto, CA: Consulting Psychologists Press.

Srull, T. J., \& GaElick, L. (1984). General principles and individual differences in the self as a habitual reference point: An examination of self-other judgments of similarity. Social Cognition, 2, 106-119.

Turner, R. G. (1980). Self-consciousness and memory of trait terms. Personality and Social Psychology Bulletin, 6, 273-277.

(Manuscript received for publication December 13, 1983.) 